\title{
EDITORIAL
}

\section{What is the best way to care for frail older adults?}

DOI:http://dx.doi.org/10.5770/cgj.16.98

Hello! We are pleased to present our third issue of The Canadian Geriatrics Journal for 2013. This issue examines some of the current work being done in Canada on caring for frail older adults.

Dr. Robert Lam has examined retrospectively what medical issues arise in a Care of the Elderly physician's office, in an attempt to provide evidence to better match future Continuing Medical Education activities with the issues that are actually seen in the office. This study nicely leads into the work done by Dr. Jayna Holroyd-Leduc, who performed a series of focus groups of Alberta health-care providers that examined ways to improve care for frail older adults using clinical care pathways. Dr. Philip St. John explores some psychological contributors to frailty through a prospective longitudinal investigation of how the acceptance of disability as a part of aging can itself be a risk factor for becoming frail. The issue of when to tell a frail older adult to stop driving is a common concern in most clinical practices involving older adults. Dr. Mononita Roy suggests a new approach to this issue through a systematic review of using the Trails B test to predict driving risk. Dr. Ken Rockwood has also reviewed a recent work from Oxford University Press examining both the co-morbidities and cognitive issues that contribute to frailty, "Chronic Medical Disease \& Cognitive Aging: Toward a Healthy Body and Brain" (edited by Kristine Yaffe).

Hope everyone has enjoyed a wonderful summer!

Cheers,

Dr. Kenneth M. Madden

Editor-in-Chief

Canadian Geriatrics Journal 